\title{
ГЕНДЕРНЫЕ И СОЦИАЛЬНО-ПСИХОЛОГИЧЕСКИЕ АСПЕКТЫ ИНТОЛЕРАНТНОСТИ, КАК ОСНОВЫ РАЗВИТИЯ ЭКСТРЕМИСТСКИХ НАСТРОЕНИЙ В МОЛОДЕЖНОЙ СРЕДЕ 1
}

\section{GENDER AND SOCIO-PSYCHOLOGICAL ASPECTS OF INTOLERANCE AS A BASIS FOR THE DEVELOPMENT OF EXTREMIST MOOD IN YOUTH ${ }^{2}$}

\section{Idrisov \\ I. Khazhuev}

Summary: The article presents the results of a study of the influence of gender and socio-psychological factors on the formation of intolerance and extremist sentiments in the youth environment. The presence of gender-related differences in the parameters of the severity of the qualities of tolerance (ethnic, social and personal), socio-psychological attitudes in the motivational-need sphere, susceptibility to the experiences of intense stress reactions of a post-traumatic nature, the formation of certain mechanisms of coping strategies and the levels of development of certain characteristics of emotional intelligence were revealed. Consideration of the features of the development of these constructs in the context of the formation of extremist sentiments in the youth environment made it possible to study the potential impact and influence of certain socio-psychological qualities of the individual on the formation and formation of extremist and antisocial beliefs of the individual.

Keywords: extremist moods, aggression, tolerance, traumatic event, motivation, personality.
Идрисов Кюри Арбиевич

Д.м.н., профессор, ФГБОУ ВО «Чеченский государственный педагогический университет»; ФГБОУ ВО «Чеченский государственный университет» г. Грозный

kyuri.idrisov@yandex.ru

Хажуев Ислам Сайдахмедович

дочент, ФГБОУ ВО «Чеченский государственный педагогический университет», г. Грозный

hazhuev@mail.ru

Аннотация: В статье представлены результаты исследования влияния гендерных и социально-психологических факторов на формирование интолерантности и экстремистских настроений в молодежной среде. Выявлено наличие гендерно обусловленных различий в параметрах выраженности качеств толерантности (этнической, социальной и личностной), социально-психологических установок в мотивационно-потребностной сфере, подверженности переживаниям интенсивных стрессовых реакций посттравматического характера, формирование определенных механизмов копинг-стратегий и уровни развития отдельных характеристик эмоционального интеллекта. Рассмотрение особенностей развития данных конструктов в контексте формирования экстремистских настроений в молодежной среде позволило изучить потенциальные воздействия и влияния определенных социально-психологических качеств индивида на становление и формирование экстремистских и антисоциальных убеждений личности.

Ключевые слова: экстремистские настроения, агрессия, толерантность, психотравмирующее событие, мотивация, личность.
$M$ олодежная среда, традиционно, в силу своих социальных характеристик и остроты восприятия окружающей обстановки, является той частью общества, в которой наиболее быстро и взрывоопасно происходит накопление и реализация негативного протестного потенциала [6].

В обыденной реальности молодежный экстремизм выражается в пренебрежении к действующим в обществе правилам поведения, к закону в целом, появлении неформальных молодежных объединений противоправного характера. При этом развитие молодежного экстремизма - это свидетельство недостаточной социальной адаптации самой молодежи, развития асоциаль- ных установок в сознании молодых людей $[11 ; 12]$

Вместе с тем любые социальные явления возникают не вдруг и случайно по прихоти отдельного человека или группы людей, а имеют свои исторические корни и вполне конкретные предпосылки в реалиях современной жизни [21, С.169]. Согласно различным источникам, количество насильственных преступлений экстремистского характера, совершаемых молодежью, имеет тенденцию постоянного роста $[6 ; 27 ; 28 ; 29 ; 30]$.

Как отмечают специалисты, наиболее часто совершают преступления лица в возрасте 13-25 лет, а совершенные преступления носят агрессивно-насильственный

\footnotetext{
1 Исследование выполнено при финансовой поддержке Российского фонда фундаментальных исследований (РФФИ) в рамках научного проекта № 20-013-00239.

2 The reported study was funded by Russian Foundation for Basic Research (RFBR), project number 20-013-00239.
} 
характер $[11 ; 27 ; 29 ; 30 ; 31]$. При этом очень часто молодежь подверженная экстремистским воззрениям старается ретранслировать собственные взгляды на более широкую общественность [25; 26; 27$]$.

Как указывают результаты исследований зарубежных авторов, и агрессивные подростки-школьники, радикалы-джихадисты, прибегающие к актам насилия имеют некоторые сходства в использовании публичного пространства при реализации экстремистских действий, которые носят исключительно символическое значение [27].

В то же время, в современном западном обществе, этническая нетерпимость претерпела некоторые изменения, однако она не исчезла полностью, а трансформировалась в формы расизма, который исходить от низших слоев общества [6; 19].

Причины роста экстремизма в современном обществе, по мнению различных специалистов $[1 ; 2 ; 5 ; 10 ; 14$; $22 ; 29 ; 30 ; 31]$, в значительной степени связаны с произошедшими в результате глобализации трансформаций системы морально-нравственных ориентиров, ухудшения качества образования, снижения политической и правовой свободы на фоне усилившихся миграционных процессов $[4 ; 15]$.

Если говорить об интолерантных проявлениях в молодежной среде, то приходится признать, что это часто весьма слабо дифференцированная форма осознанной активности молодых людей, имеющая обоснование либо в форме стройной идеологической концепции, либо - чаще - в виде обрывочных символов, архетипов, лозунгов [15, С.220].

В качестве объектов интолерантности могут выступать: раса, национальность, цвет кожи, инвалиды, старики, дети, сексуальные меньшинства, люди с проблемами со здоровьем, люди с психическими отклонениями, странные люди, религиозные группы, политические взгляды и т.Д., и т.п. [6, С.67]. Крайним поведенческим проявлением интолерантности чаще выступает экстремизм. В целом под экстремизмом понимается биологический и социально-психологический феномен, в основе которого лежит превышение пределов допустимого при наличии злого смысла или умысла [18.].

Естественно, любая форма насилия в обществе, в том числе проявляющаяся в виде экстремисткой и террористической деятельности, вызывается целым комплексом причин - биологических, психологических, экономических, политических и т. д. Как отмечает М.К. Арчаков, агрессия, высвобождаемая индивидом посредством подобной деятельности, нередко связана с проявлением враждебности, даже если она носит вполне «доброкаче- ственный» характер. При этом человеческая агрессивность, то есть открытая враждебность, неприятие чеголибо (например, расизм, антисемитизм, шовинизм и др.) выступает в качестве одного из элементов экстремистской деятельности [3; 8; 13].

Таким образом, делая вывод из краткого теоретического анализа проблемы подверженности личности в современном мире интолерантности и экстремистским наклонностям, важно отметить, что в основе подобных форм поведения и самовыражения личности находятся как социально-психологические (бытовая неустроенность, социальная дезадаптация, субъективно осознаваемое отсутствие жизненных перспектив, наличие личностных проблем психологического и иного плана), так и демографические (пол и возраст) детерминанты, которые взаимодействуя определяют интенсивность и глубину проявления экстремисткой деятельности.

Несмотря на значительную проработанность вопросов влияния демографических и психосоциальных факторов на формирования деструктивных форм мышления и поведения, остаются малоизученными гендерные и психосоциальные факторы формирования идей и поведения террористической и экстремисткой направленности среди молодежи народов Северного Кавказа в целом и Чеченской Республики в частности. В связи с этим целью нашего исследования стало изучение влияния гендерных и социально-психологических факторов на формирование интолерантного и экстремистского мировоззрения среди молодежи Чеченской Республики.

\section{Материал и методы исследования}

В исследовании приняли участие представители молодого населения Чеченской Республики в количестве 129 человек. Из числа обследованных 51(39,53\%) составили юноши и 78(60,46\%) девушки. Критериями включения в выборку было добровольное согласие на анонимной основе.

В качестве исследовательского инструментария использованы: Шкала оценки влияния травматического события (адаптация Н.В. Тарабриной); Индекс этнической толерантности (Г.У. Солдатова); Индекс ксенофобии (Е.Н. Юрасова); Методика многомерного измерения копинга (Т.Л. Крюкова); Методика диагностики социальнопсихологических установок личности в мотивационнопотребностной сфере (О.Ф. Потемкиной).

Статистический анализ осуществлялся с помощью пакета статистических программ SPSS for Windows 11.0. Анализ ранговых различий изучаемых параметров проводился с использованием непараметрических критериев Манна-Уитни и Фридмана. 


\section{Результаты исследования и их анализ}

Анализ различных исследований, посвященных изучению проблемы экстремизма и терроризма, позволяет рассматривать различные психологические конструкты (стили совладания, мотивационные установки личности, переживания посттравматического стресса, показатели интеллектуального развития и многое другое) в качестве социально-психологических и демографических детерминантов развития у личности крайних взглядов и убеждений, которые потенциально могут выражаться даже в общей террористической направленности индивида при неблагоприятных обстоятельствах и суггестивном воздействии заинтересованных лиц и экстремистских организаций.

Исходя из данного положения в настоящем исследовании были изучены показатели агрессивных реакций респондентов в разрезе гендерного признака (табл.1).

Результаты рангового анализа (табл.1) указывают на то, что девушки более склонны проявлять вербальную агрессию, тогда как юноши характеризуются склонностью к прямой физической агрессии. При этом юноши также проявляют склонность к проявлению вербальной агрессии и косвенной физической агрессии по сравнению с женщинами, однако различия по данным видам агрессивного поведения между выборками юношей и девушек не обладают статистической значимостью.

В то же время, достоверно $(p=0,013)$ наиболее частой формой агрессивного поведения среди молодежи, вне зависимости от гендерной принадлежности, оказалась склонность к прямой вербальной агрессии (при этом склонность к прямой физической агрессии чуть менее выражена), а наименее выражена - склонность к косвен- ной агрессии.

Таким образом, юноши чаще демонстрируют прямую физическую агрессию, а девушки - косвенную вербальную агрессию.

Другими важным показателями, характеризующие экстремистские типы мышления и поведения, являются ксенофобия и этническая толерантность. Анализ этих показателей, в разрезе гендерного признака, позволяет оценить степень взаимовлияния этих факторов (табл.2).

Проведенный анализ показал, что юноши характеризуется более выраженными показателями индекса ксенофобии по сравнению с группой девушек. Выявленные различия в показателях выраженности индекса ксенофобии, проведенного по признаку гендерных различий, обладают статистической значимостью $(p=0,020)$, тогда как различия показателей по субшкалам опросника этнической толерантности (у юношей и девушек) не выявили статистической значимости, хотя и имеется тенденция к тому, что девушкам более свойственны качества этнической и социальной толерантности, в то время как у юношей выражены качества толерантности как черты личности.

Анализ социально-психологических установок личности в мотивационно-потребностной сфере (диагностированных при помощи методики О.Ф. Потемкиной), позволил получить важные сведения о доминирующих установках обследуемых, с одной стороны это ориентация на труд, свободу, власть, деньги, с другой стороны на процесс, результат, альтруизм и эгоизм. Все эти факторы рассматриваются через гендерный признак.

Согласно результатам рангового анализа (на основе применения критерия Манна-Уитни) выявлено, что юно-

Распределение выраженности агрессии по гендерному признаку, $(n=118)$

\begin{tabular}{|c|c|c|c|c|}
\hline Переменные исследования & Пол & $\mathrm{N}$ & Средний ранг & Р-значимость \\
\hline \multirow[t]{2}{*}{ Склонность к прямой вербальной агрессии } & Мужчины & 51 & 61,56 & \multirow[t]{2}{*}{0,692} \\
\hline & Женщины & 67 & 58,76 & \\
\hline \multirow[t]{2}{*}{ Склонность к косвенной вербальной агрессии } & Мужчины & 51 & 41,13 & \multirow[t]{2}{*}{$0,000^{*}$} \\
\hline & Женщины & 67 & 66,05 & \\
\hline \multirow[t]{2}{*}{ Склонность к косвенной физической агрессии } & Мужчины & 51 & 65,11 & \multirow[t]{2}{*}{0,282} \\
\hline & Женщины & 67 & 57,50 & \\
\hline \multirow[t]{2}{*}{ Склонность к прямой физической агрессии } & Мужчины & 51 & 77,77 & \multirow[t]{2}{*}{$0,000^{*}$} \\
\hline & Женщины & 67 & 52,99 & \\
\hline \multirow[t]{3}{*}{ Общий индекс агрессии } & Мужчины & 51 & 62,66 & \multirow[t]{2}{*}{0,548} \\
\hline & Женщины & 67 & 58,37 & \\
\hline & Всего & 118 & & \\
\hline
\end{tabular}

Примечание: * - статистическая достоверность $\mathrm{p}<00,1$ 
шам более свойственно ориентация на свободу $(\mathrm{p}=0,021)$ и власть $(p=0,048)$. Кроме того, показатели ориентации на труд и ориентация на деньги также преобладали у юношей, по сравнению с аналогичным показателями у девушек, хотя эти различия и не имели статистической достоверности.

У группы девушек достоверно доминирует ориентация на альтруизм ( $p=0,015)$. Ориентация на эгоизм также преобладает у девушек, по сравнению с юношами, которые, в свою очередь, отличаются большей ориентированностью на процесс и результат.

Анализ различий выраженности признаков посттравматического стресса по гендерному признаку показывает большую подверженность развитию интенсивных стрессовых переживаний у девушек. Результаты настоящего исследования повторяют данные, полученные в исследованиях, проведенных ранее среди населения Чеченской Республики.

В контексте рассматриваемой проблемы важно было также выявить гендерные особенности развития интенсивных стрессовых переживаний как неблагоприятных социально-психологических факторов формирования экстремистских мировоззрений и механизмов совладания - индивидуально-личностных диспозиций, определяющих особенности преодоления индивидом последствий переживаний психотравмирующих событий.

Так, полученные данные показали, что выборка девушек более сильно подвержена переживаниям симптомов посттравматического стресса, которые в совокупности и при высокой интенсивности могут корреспондировать с клиническим уровнем посттравматического стрессового расстройства. Как показал анализ, показатели трех критериев посттравматического стресса, диагностированных при помощи ШОВТС - вторже- ние $(p=0,000)$, избегание $(p=0,002)$ и физиологическая возбудимость $(p=0,001)$ достоверно более выражены у девушек, по сравнению с аналогичными показателями у юношей.

Полученные данные при рассмотрении в контексте социально-психологической интолерантности, как основы развития экстремистских настроений, указывают на то, что выборка девушек в большей мере относится к группе риска из-за высокой степени выраженности интенсивных стрессовых переживаний и подверженности развитию на их фоне патологии посттравматического характера.

Как известно у лиц, переживших травматический стресс и страдающих посттравматическими стрессовыми реакциями, возможно развитие различных психопатологических нарушений, приводящих к развитию социальной, профессиональной и семейной дезадаптации. Внутренняя картина мира таких людей, деформированная травматическими переживания прошлого, может стать с одной стороны, ретранслятором пережитого ими негативного опыта (сопряженного с насилием и агрессивным поведением), а с другой стороны повышает их уязвимость и восприимчивость для идеологического воздействия со стороны отдельных лиц, экстремистских и тоталитарных сект, со всеми вытекающими отсюда последствиями. Именно этим обстоятельством можно попытаться объяснить часть случаев переезда женщин из Северного Кавказа в зону боевых действий на Ближнем Востоке, под предлогом замужества.

Анализ копинг-стратегий, используемых молодыми людьми в соответствии со своей гендерной принадлежностью, позволил выявить стратегии поведения, используемые молодыми людьми в сложных жизненных ситуациях.

Таблица 2.

Распределение выраженности показателей этнической толерантности и ксенофобии по гендерному признаку, $(n=118)$

\begin{tabular}{|l|l|c|c|c|}
\hline \multicolumn{1}{|c|}{ Переменные исследования } & \multicolumn{1}{|c|}{ Пол } & N & Средний ранг & Р-значимость \\
\hline \multirow{2}{*}{ Индекс ксенофобии } & Мужчины & 51 & 71,71 & \multirow{2}{*}{$0,020^{*}$} \\
\cline { 1 - 4 } & Женщины & 67 & 55,15 & \\
\hline \multirow{2}{*}{ Субшкала «этническая толерантность» } & Мужчины & 51 & 55,56 & \multirow{2}{*}{0,454} \\
\cline { 2 - 4 } & Женщины & 67 & 60,90 & \\
\hline \multirow{2}{*}{ Субшкала «социальная толерантность» } & Мужчины & 51 & 52,35 & \multirow{2}{*}{0,174} \\
\cline { 2 - 5 } & Женщины & 67 & 62,05 & \multirow{2}{*}{0,688} \\
\hline \multirow{2}{*}{ Субшкала «толерантность как черта личности» } & Мужчины & 51 & 61,61 & \\
\cline { 2 - 4 } & Женщины & 67 & 58,75 & \\
\cline { 2 - 4 } & Всего & 118 & & \\
\hline
\end{tabular}

Примечание: * - статистическая достоверность p<00,1 
Так выявленные различия указывают, что юноши чаще, чем девушки, используют в стрессовых ситуациях такие стратегии совладания как проблемно-ориентированный стиль ( $p=0,018)$, стиль совладания посредством избегания $(p=0,044)$ и социального отвлечения $(p=0,40)$, хотя статистической достоверностью по гендерному признаку обладает только различие в частоте использования юношами механизмов совладания, ориентированных на решение и избегание задачи/проблемы ( $p=0,005)$. Среди девушек наиболее популярными стилями совладания оказались - копинг, ориентированный на эмоциональное решение проблемы и копинг отвлечения. Однако различия по этим стратегиям совладания не имеют статистической значимости.

В то же время анализ параметров эмоционального интеллекта в зависимости от гендерного признака позволил выявить достоверные различия между юношами и девушками только по показателям выраженности шкалы управления своими эмоциями $(p=0,019)$.

У девушек, по сравнению с юношами, более выра- жены показатели эмоциональной осведомленности и эмпатии, являющиеся составными элементами общего эмоционального интеллекта. У юношей достоверно преобладают показатели эмоциональных свойства интеллекта, ответственные за управление эмоциями.

Управление собственными эмоциями является важной характеристикой эмоционального интеллекта, которая может способствовать сдерживанию агрессивных побуждений и негативных тенденций личности, ограничивая тем самым впадение в крайние действия, в том числе и действия экстремистского характера. Для юношей, как показали результаты исследования, более свойственно проявление не только прямой вербальной агрессии, но и ксенофобии, что может граничить с экстремистским поведением личности. Девушки обладают склонностью к развитию негативных реакций посттравматического стресса, сопряженных с различными формами дезадаптации, у них менее развиты свойства, ответственные за управление собственными эмоциями и слабо выражен механизм совладания, ориентированный на конструктивное решение проблемы.

\section{ЛИТЕРАТУРА}

1. Андреев Ю.Н. Основы противодействия экстремизму и терроризму: конспект лекций / Ю.Н. Андреев, О.Н. Викторов. - Чебоксары: Изд-во Чуваш. ун-та, 2013. -99 c.

2. Абдрахманов Д.М., Максимов К.В., Нугуманов М.М., Сафина Э.Н. Экстремизм. 100 ответов на насущные вопросы об экстремизме и терроризме. Информационно-справочное пособие. - Уфа: Мир печати. - 2018. - 80 с.

3. Арчаков М.К. Политический экстремизм: сущность, проявления, меры противодействия: монография / М.К. Арчаков; под научной редакцией Ю.А. Ермакова. - Москва: Издательство Юрайт, 2020. — 295 с.

4. Баева Л.В. Экстремизм: природа и формы проявления [Текст] / Л.В. Баева // Каспийский регион: политика, экономика, культура. - 2008. - № 3 (16). C. 21-26.

5. Белашева И.В., Ершова Д.А, Есаян М.Л. Психология терроризма: учебное пособие. - Ставрополь: Изд-во СКФУ. - 2016. - 120 с

6. Бобрышов С.В., Саенко Л.А. Проявления ксенофобии и межнационального экстремизма в современной молодёжной среде Международно-правовые средства противодействия терроризму в условиях глобализации. Проблемы террористического наемничества среди молодежи и пути их преодоления: сб. материалов Всероссийской научно-прак. конф. - Ставрополь: СГПИ. - 2016. -С.66-68

7. Крюкова Т.Л. Методы изучения совладающего поведения: три копинг- шкалы. - Кострома: «Авантитул». - 2007. - 60 с.

8. Лоренц К. Агрессия, или, Так называемое зло. - М.: АСТ. - 2017. - 350 с.

9. Левитов Н.Д. Психическое состояние агрессии // Вопросы психологии. 1972. - № 6. - С. 168-173.

10. Осипова Н.В. — Социокультурные детерминанты экстремистского поведения // Социодинамика. - 2016. - № 6. - С. 1 - 12.

11. Профилактика проявлений экстремизма и ксенофобии в образовательной среде: Методические рекомендации. - АСОУ. - 2011. - 48 c.

12. Профилактика экстремизма в молодежной среде: учебное пособие для вузов // А.В. Мартыненко [и др.]; под общей редакцией А.В. Мартыненко. М.: Издательство Юрайт. - 2020. - 221 с.

13. Психоанализ в трудах зарубежных авторов. СПб. - 2006. С. 79.

14. Психология формирования антитеррористических ценностей студентов современного университета: учебник // под ред. И.В. Абакумовой, П.Н. Ермакова. - М.: КРЕДО. - 2013. - 352 с.

15. Селиванова 0.А. Проблемы профилактики интолерантных взаимоотношений в условиях высшего учебного заведения // Вестник Тюменского государственного университета. 2012. -№1. С.216-221

16. Солдатова Г.У., Кравцова 0.А., Хулаев 0.Е. и др. Психодиагностика толерантности // Психологи о мигрантах и миграции в России: инф. - аналит бюллетень. - М. - 2002. - № 4. - С. 59-65.

17. Тарабрина Н.В. Практическое руководство по психологии посттравматического стресса. В 2Ч. Ч.2. Бланки методик. - М.: «Когито-Центр». - 2007. - 77 с. (Психологический инструментарий).

18. Томалинцев В.Н. Введение в социальную экстремологию: учеб. пособие/Томалинцев В.Н., Козлов А.А. СПб.: Изд-во С.-Петерб. ун-та, 2005 
19. Фирсов М.В., Студинова Е.Г. Теория социальной работы. М.: Гуманит. изд. центр ВЛА ДОС, 2001. — 432 .

20. Фрейд 3. Введение в психоанализ. Лекции. - М. - 2007. - С. 67-81.

21. Хазиев В.С., Олейник В.С. Детерминанты экстремизма и терроризма. // Противодействие распространению идеологии экстремизма и терроризма среди молодежи: Материалы Межрегиональной научно-практической конференции по профилактике экстремизма (г. Уфа, 24 мая 2017 г.) / Составители: Д.М. Абдрахманов, Ю.И. Малахов, Р.Р. Мухитдинова, 3.Л. Сизоненко, Ш.Б. Эргашева. - Уфа: Изд-во «Мир печати», 2017. - С.169-182

22. Хромов В.Д. Психологические аспекты противодействия экстремизму и терроризму // 0бзор.НЦПТИ. - 2018. - №4 (15).

23. Юрасова Е.Н. Психологические особенности лиц,склонных к экстремизму, терроризму и ксенофобии // «Юридическая психология». - 2008. - №4. C.27-35.

24. Berntzen, Lars Erik/Weisskircher, Manès (2016): Anti-Islamic Pegida Beyond Germany: Explaining Differences in Mobilisation. Journal of Intercultural Studies, 37 (6), S. 556-573.

25. Böckler N., Hoffmann J. \& Zick A. (2015). The Frankfurt airport attack: A case study on the radicalization of a lone-actor terrorist. Journal of Threat Assessment and Management, 2, 153-163. 10.1037/tam0000045

26. Böckler N., Roth V., Stetten L. \& Zick A. (2014). Targeted school violence and the web of causes: Risk factors and the problems of specificity. Commentary on: "Bullying, romantic rejection, and conflicts with teachers: The crucial role of social dynamics in the development of school shootings - A systematic review". International Journal of Developmental Science, 8, 49-51. 10.3233/DEV-140146

27. Böckler Nils/Leuschner, Vincenz/Zick, Andreas/Scheithauer, Herbert (2018): Same but Different? Developmental Pathways to Demonstrative Targeted Attacks Qualitative Case Analyses of Adolescent and Young Adult Perpetrators of Targeted School Attacks and Jihadi Terrorist Attacks in Germany. International Journal of Developmental Science, 12 (1), S. 5-24.

28. Hartleb F. (2017). Rechtsterrorismus statt Amoklauf. Eine notwendige Neubewertung des Attentats von München am 22. Juli 2016 [Right-wing terrorism instead of rampage. A necessary reassessment of the Munich Attack on 22nd July, 2016]. Kriminalistik, 12/2017, 715-722.

29. Kruglanski A. \& Fishman S. Psychological Factors in Terrorism and Counterterrorism: Individual, Group, and Organizational Levels of Analysis // Social Issues and Policy Review. - 2009. - 3. 1 - 44. 10.1111/j.1751-2409.2009.01009.x.

30. Oppetit A., Campelo N.,Bouzar L.,Pellerin H., Hefez S., Bronsard G., Bouzar D., Cohen D. Do Radicalized Minors Have Different Social and Psychological Profiles From Radicalized Adults?// Frontiers in Psychiatry. - 2019. - 10.644. D0l: 10.3389 / fpsyt.2019.00644.

31. Trip S., Marian M.I., Halmajan A., Drugas M.I., Bora C.H., and Roseanu G. (2019) Irrational Beliefs and Personality Traits as Psychological Mechanisms Underlying the Adolescents' Extremist Mind-Set // Front Psychol. - 2019. - 10: 1184. doi: 10.3389/fpsyg.2019.01184

( ) Идрисов Кюри Арбиевич (kyuri.idrisov@yandex.ru), Хажуев Ислам Сайдахмедович (hazhuev@mail.ru).

Журнал «Современная наука: актуальные проблемы теории и практики»

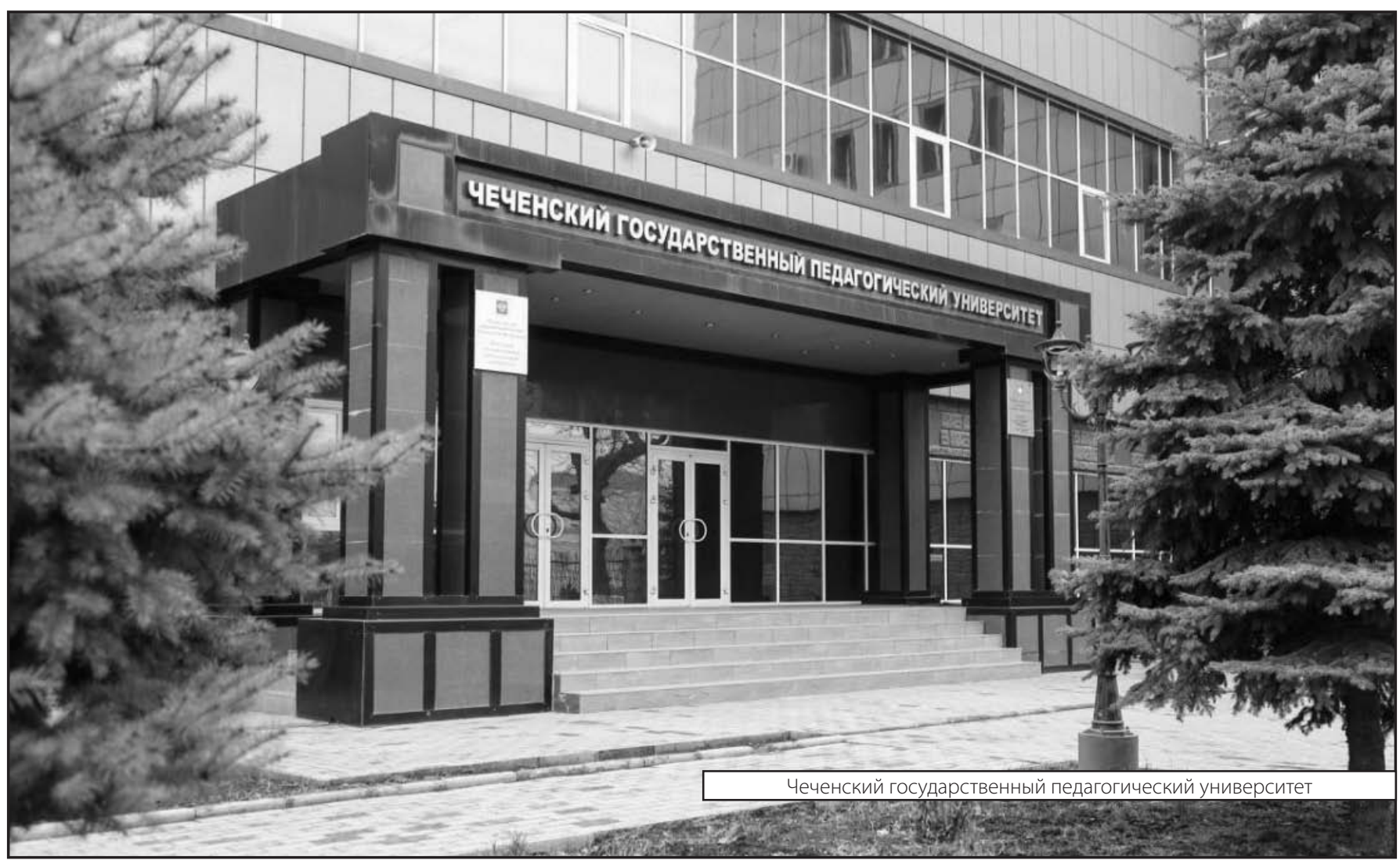

